\title{
La estrategia disruptiva y la complejidad
}

\author{
Dr. Roberto Serra \\ (Presidente Fundador de la Sociedad Latinoamericana de Estrategia) SLADEProfesor \\ Titular de la Facultad de Ciencias Económicas \\ Universidad de Buenos Aires, Argentina \\ robertoserra77@gmail.com
}

Recepción: 10/05/2021

Aceptación: 17/06/2021

\section{Resumen}

Este artículo resume lo que pienso sobre la estrategia y su complejidad. La estrategia no se puede aprender de libros de Estrategia hay que interrelacionar todas las disciplinas para poder tomar decisiones estratégicas sostenibles en el tiempo.

La estrategia está basada en entender las emociones, los modelos mentales, el entorno, los consumidores los jugadores clave y fundamentalmente trabajar en temas espirituales para poder lograr un equipo que se desarrolle alegre, con intensidad relajada y Pasión. La importancia de los individuos en la Estrategia es vital para cualquier organización incluyendo los países. La estrategia disruptiva es muy importante en un mundo VUCA como el actual. La disrupción proviene de la innovación, de romper con lo existente y crear algo nuevo y diferente pero siempre que sea aceptado por los clientes, el público objetivo o la comunidad.

\section{"La Estrategia es una apuesta dinámica para lograr la Visión con el Posicio- namiento deseado" (Roberto Serra, 2020)}

La estrategia es claramente una apuesta, apuesto a elegir qué quiero hacer y qué no quiero hacer, pongo fichas en algo dejando de lado otras opciones. Elegir una estrategia implica riesgo y coraje, hay que apostar y tomar una decisión en parte racional y en parte emocional pero la decisión más importante para cualquier organización.

La estrategia tiene que ser dinámica, por esto trabajamos con la idea de un marco integrador y no un plan muy estructurado. La estrategia tiene que ser evolutiva y disruptiva en forma permanente y dinámica. 


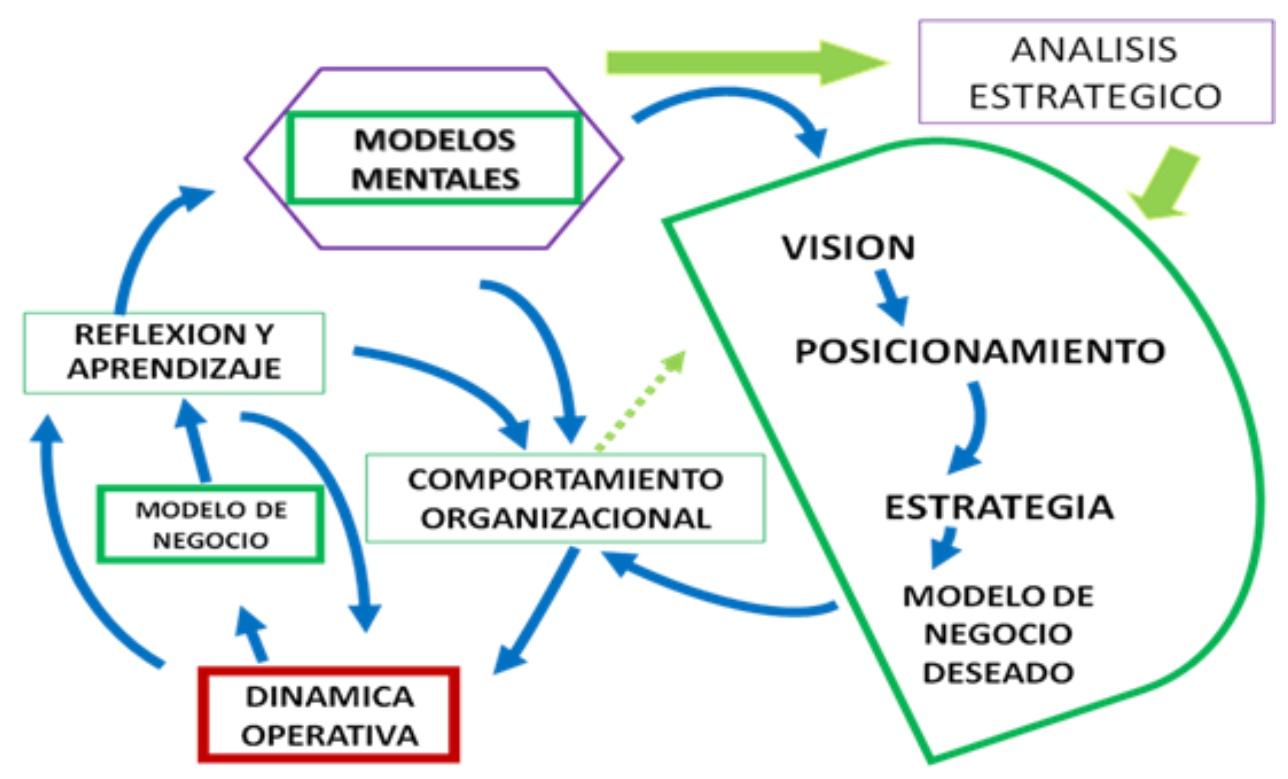

En los últimos años, diferentes factores van transformando el modo en que las organizaciones deben generar el cambio para poder desarrollarse en el tiempo.

Una organización que no se mueva a alta velocidad en la dirección correcta está condenada al fracaso. Ya no se puede manejar una empresa en forma fragmentada, donde cada área es responsable de una parte del proceso. Por ejemplo, hay especialistas para cada área: el comprador tradicional es responsable de negociar, comprar y lograr un margen adecuado para la cadena, el gerente de ventas es responsable de vender al costo más bajo posible. Entonces tenemos las típicas batallas entre operaciones y comercial, a esto se agrega el área de marketing que toma sus propias decisiones en cuanto a promociones y además finanzas que requiere que los números se ajusten al presupuesto que cada sector hizo. Esta filosofía de manejo de una cadena minorista es la que encontramos en líneas generales en muchos países del mundo, lo cual nos llevaría a pensar que si todos cumplen con sus objetivos y su presupuesto, la empresa como un todo cumpliría también los objetivos; pero lamentablemente en la mayoría de los casos no es así. Esta filosofía proviene del paradigma de simplicidad y las leyes deterministas de Newton. Para entender esta filosofía comenzaremos con los modelos mentales.

\section{Modelos mentales}

La disciplina de los modelos mentales trabaja con aquellos supuestos hondamente arraigados en nuestra conciencia y con las generalizaciones e imágenes, que influyen en nuestra manera de actuar, ver la realidad y planear acciones. Estos supuestos son el producto del aprendizaje, experiencia y patrones culturales que vamos obteniendo a lo largo de nuestras vidas.
Muchos modelos mentales están arraigados en la sociedad, algunos ejemplos sencillos son: "Las mujeres manejan mal", "Todos los policías son corruptos" y "Solo los hombres juegan fútbol". Así también tenemos los modelos mentales en las organizaciones: "No vendo, entonces bajo los precios", "No tengo rentabilidad, entonces bajo los costos".

Lo que percibimos de la realidad está determinado por nuestros paradigmas. Lo que para una persona puede resultar muy notorio, perfectamente obvio, puede ser casi imperceptible para otra persona con un paradigma diferente.

\section{Paradigma de simplicidad}

Busca orden, persigue el desorden, trata de lograr lo simple y fácil, de dividir para facilitar, de integrar para simplificar. El orden se reduce a una ley, a un principio. El principio de simplicidad o bien separa lo que está ligado (disyunción) o bien unifica lo que es diverso (reducción) (Morin, 2003)

\section{¿De quién es la culpa?}

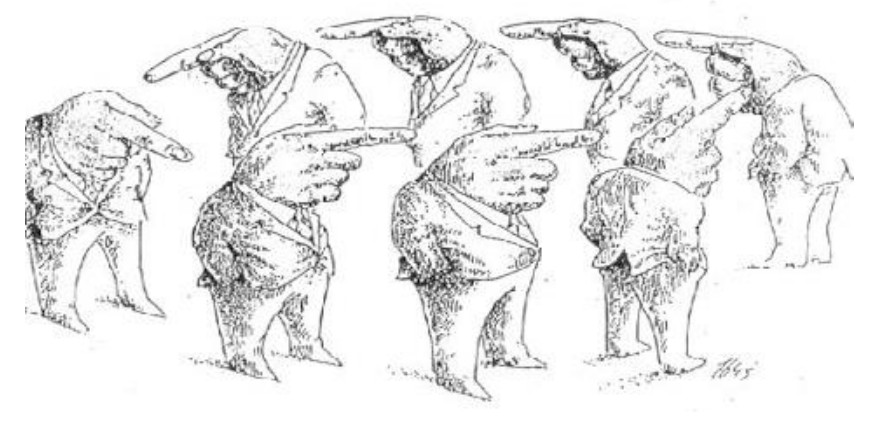


Tenemos por ejemplo al comprador que solo se dedica a negociar y comprar para que otro lo venda, pero a su vez otro distinto analice el mercado y haga la promoción correspondiente, entonces si no se vende ¿quién tiene la culpa? ¿el comprador, el vendedor o el de marketing? Esto nos obliga a buscar culpables que realmente no existen y soluciones que no llevan nunca a los resultados esperados en el mediano plazo. Estamos simplificando algo complejo, unido, que no se puede separar, tratando de reducir la complejidad en forma arbitraria y artificial, de esta forma, nunca vamos a lograr un resultado sostenible en el tiempo.

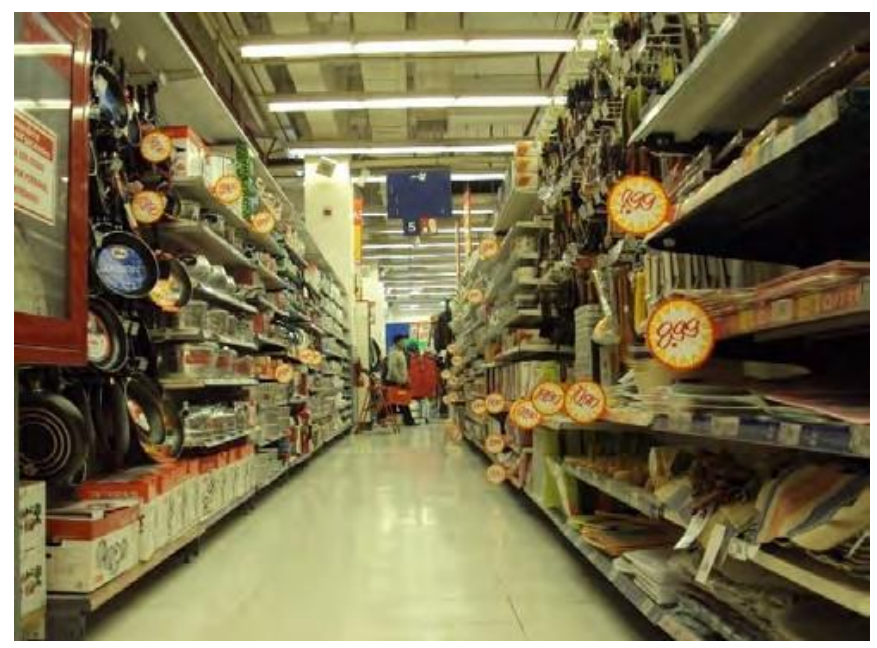

Un tipo de ejemplo del paradigma de la simplicidad es el tradicional organigrama que lo único que genera son problemas por su grado de simplificación extremo, otro ejemplo son las tradicionales góndolas lineales de los supermercados, donde solo pensamos en la optimización del espacio, de todos modos, a medida que pasa el tiempo se están utilizando mucho menos, porque el cliente no compra de forma lineal.

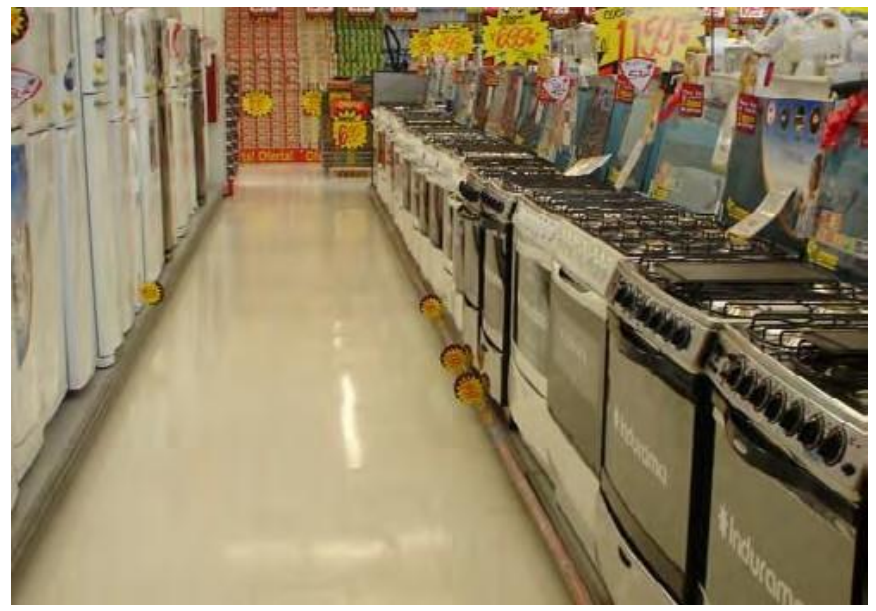

También el análisis FODA, es un típico análisis estático y lineal típico de la física de Newton y del paradigma de simplicidad, ya que no se ven los aceleradores, ni los simplificadores, ni los frenos, ni tampoco las distintas relaciones entre los elementos, no se toma en cuenta la complejidad como tejido no separable. Solo se ven los puntos débiles y fuertes las amenazas y oportunidades en forma estática y simplificada en un momento dado del tiempo, es como una foto. Esta foto en la actualidad tiene poco valor ya que la dinámica del entorno hace que quede desactualizada de un momento para otro.

Aquí un ejercicio para desarrollar; en la imagen que se muestra a continuación, se debe unir los 09 puntos usando cuatro líneas rectas y sin levantar el lápiz del papel, vamos inténtalo.

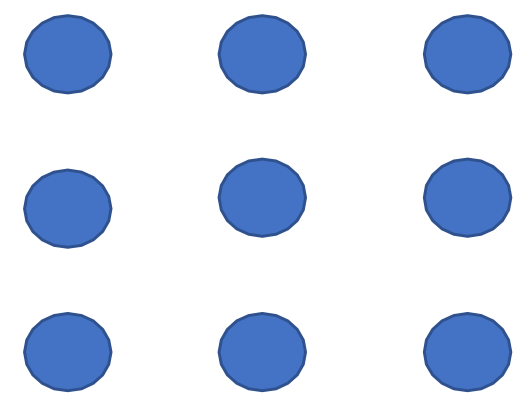

Por ejemplo en este gráfico observamos cuatro líneas rectas, pero no se llegan a unir los 09 puntos.

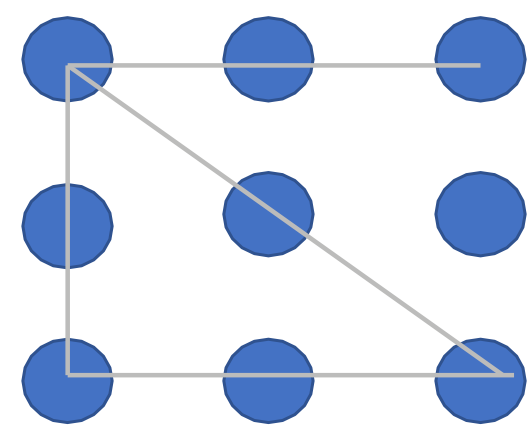

El paradigma de la simplicidad también está relacionado con el iceberg, el cual explica que lo que vemos encima del nivel del agua son los hechos fácilmente observables, en los cuales se centran las acciones de la compañía y no se llegan a grandes soluciones, sólo superficiales; sin embargo, si queremos profundizar, tenemos que ver lo que se encuentra por debajo del nivel del agua, permitiéndonos trabajar sobre la estructura y las estrategias, creando algo totalmente disruptivo y nuevo.

\section{Paradigma de la complejidad}

¿Qué es complejidad?, un tejido de constituyentes heterogéneos inseparablemente asociados. La complejidad se presenta con los rasgos de lo intrincado, enredado, 
la ambigüedad, la incertidumbre, de allí la necesidad para el conocimiento, de poner orden en los fenómenos rechazando el desorden, de descartar lo incierto; es decir, de seleccionar los elementos de orden y de certidumbre. La complejidad es un tejido formado por todas las relaciones posibles, está basada en la física cuántica, la física de las relaciones, la noción de "non locality", significa que los objetos o las personas estén separadas, están siempre "juntas pero aparte". El concepto de "non locality" es el núcleo básico de la física cuántica, como el concepto de locality era el núcleo de la física newtoniana.

El paradigma de la complejidad nos enseña que debemos trabajar juntos o integrados, aunque estemos separados, debemos entender todo lo que nos rodea aunque no esté muy cerca de nosotros, que deben integrar no fragmentar como lo hacíamos en el paradigma tradicional de simplicidad. Implica una nueva forma de pensamiento, un nuevo modelo mental.

"Los modelos mentales son las imágenes, supuestos e historias que llevamos en la mente acerca de nosotros, los demás, las instituciones y todos los aspectos del mundo. Como un cristal que distorsionan sutilmente nuestra visión, los modelos mentales determinan lo que vemos"

(Senge, 1990)

La estrategia se forma en la mente de las personas que componen la empresa. Por esta razón es que comenzamos el análisis de la estrategia a partir del desarrollo del concepto de modelo mental.

La lógica de los modelos mentales tradicionales siente que necesita la autoridad para manejar la organización. También son muy importantes los recursos y la asignación a una estructura, representada por el organigrama y basada en la jerarquía y en la división del trabajo. Esta división del trabajo es la base de la fragmentación, sobre la cual construye un sistema de control para poder lograr los resultados deseados. El instrumento básico de presión dentro de este modelo mental para el manejo de una organización es el presupuesto.

Esta forma de manejo resalta, además, la importancia del manejo de los recursos. En las grandes empresas uno de los departamentos "clásicos" resulta ser el de costos. Se busca eficiencia, no a través de mejores negocios, sino a costa de una cantidad de recursos comprometidos. Los especialistas hablan de downsizing y resizing y la empresa se entretiene mirando su propio ombligo.

Este modelo mental, en resumen, prioriza cuidar, culti- var y racionalizar el pasado (sus recursos, su estructura, etc., son "bienes" que no hay que perder, dicen) y proyectar el futuro matemáticamente, estimando el futuro en función a la experiencia pasada de la compañía.

El nuevo modelo mental que llamamos "Modelo Mental Holístico" necesario para manejar las organizaciones del siglo XXI parte de la visión, que es la imagen dinámica del futuro qué quiere lograr la organización. Sin visión no tiene sentido conducir una organización. A partir de allí, se puede definir el posicionamiento requerido para enfocar esa visión. Sin posicionamiento, una organización no tiene ningún valor. También es necesario tener coraje para romper las reglas de juego existentes y poder crear otras nuevas. Finalmente se necesita un alto nivel de comunicación interna y externa y una integración entre los miembros de la organización, sus proveedores, clientes, accionistas y la comunidad.

La empresa que tiene este empresario, al contrario del anterior, es mucho más abierta, pendiente de los movimientos del entorno, comprometida con la satisfacción de sus clientes. Es la empresa que fabrica lo que se vende, y si lo que los consumidores quieren comprar no lo están produciendo, cambia la fábrica, consigue otros proveedores o lo desarrolla. Es aquella que se compromete con las necesidades y deseos de sus clientes y sus satisfactores posibles, no es la que se ata a los productos. Es la que ve el cambio como una oportunidad, que rompe con sus propios paradigmas y juega, como en el ajedrez, pensando en lo que ocurrirá varias jugadas más adelante. Como la realidad es mucho más rápida que el cálculo, sus mediciones muchas veces son cualitativas, tratando de encontrar sensaciones, cambios de tendencias y movimientos en el mercado mucho antes que estos se traduzcan en números.

El modelo Mental Holistico, permite ver el todo y los detalles al mismo tiempo, entender que una organización es parte de un todo integrado que podemos llamar Ecosistiema, donde los proveedores, los clientes, la comunidad forma el todo. No se puede manejar una empresa en estos días sino manejamos el ecosistema en su conjunto.

\section{Las organizaciones y el pensamiento sis- temico}

La idea de la dinámica de sistemas surge de la mano de Jay Forrester, profesor del M.I.T, a comienzos de la década del 60 con su libro Dinámica Industrial, nombre original que luego se modificó a Dinámica de Sistemas. Durante la década del ' 90 tuvieron difusión una serie de conceptos relacionados con el pensamiento sistémi- 
co que pasaron a formar parte del lenguaje diario de las organizaciones a través de La Quinta Disciplina (Senge, 1990).

La Dinámica de Sistemas nos ayuda a comprender cómo una decisión tomada aquí y ahora, puede impactarnos en el futuro o en un lugar diferente del esperado. Y comprender cómo las raíces de nuestros problemas actuales, se encuentran en decisiones que tomamos tiempo atrás o en otro lugar y que no siempre sabemos conectar.

La dinámica de sistemas ayuda a entender que no existen las situaciones aisladas del tipo causa efecto. Vivimos en un mundo circular en movimiento, donde cada acción se basa en condiciones presentes y afecta el futuro, de manera que las condiciones modificadas pasan a ser la base de acciones futuras. El proceso no tiene inicio ni fin, sino infinitos loops de realimentación que interconectan personas y eventos.

El pensamiento sistémico exige considerar los distintos factores que influyen sobre un suceso, para entender cómo los conceptos básicos contribuyen a un resultado final, y anima a los participantes a actuar como aprendices activos, antes que como oyentes pasivos. Entender el pensamiento sistémico es, de alguna manera, aprender un lenguaje nuevo y, a la vez, una forma diferente de ver el mundo. Comenzamos incorporando conceptos, entendiendo relaciones, construyendo estructuras, hasta que, una vez obtenida una comprensión más abarcadora del concepto, y con la práctica continua, se llega a una perspectiva nueva.

Vivimos en un mundo de sistemas e interconexiones de redes. Nuestro cuerpo es un sistema, nuestras creencias y valores son sistemas, una familia, un club, una empresa es un sistema. No podemos entender ninguno de estos sistemas con simples modelos de relación causa-efecto. Sin embargo, caemos una y otra vez en la misma trampa. El pensamiento sistémico es esencial para un mundo cambiante, que cada vez se vuelve más y más complejo.

\section{Principios del pensamiento sistémico}

El principio de interconectividad implica entender como todo está conectado con todo, como todos los factores son interdependientes. Las ideas de descentralización y centralización dejan de ser validas en las empresas como formas de estructurar decisiones. Se necesita comenzar a plantear soluciones en términos de interconectividad, la dependencia e independencia dejan de ser válidas y emerge el concepto de interdependencia.
La complementariedad se basa en la idea de que los sistemas puedan complementarse para sumar, para crecer en lugar de competir. En general, distintos actores pueden vincularse en cuatro tipos de relaciones diferentes, dependiendo de la compatibilidad de sus objetivos: conflicto, cooperación, competencia o coalición. Complementarse significa agrandar el sistema total. Competir significa dividir.

La idea de incertidumbre significa que no se puede conocer el futuro totalmente, no es posible conocer toda la información acerca de una situación dada. De acuerdo al Principio de Incertidumbre de Heisenberg "aquellos que quieran crear estructuras, diseñar estrategias o tomar decisiones están siempre destinados a atrapar sombras en la niebla" (Zohar, 1997)

El cambio está presente en todo lo que hacemos, y todos los fenómenos no lineales son irreversibles: no volvemos a pasar nunca por el mismo punto ni los fenómenos se repiten de la misma manera. Las soluciones del pasado, aun las más exitosas, son válidas en el pasado. No pueden extrapolarse de manera literal, porque las condiciones son otras, los patrones diferentes aun cuando los síntomas aparezcan como similares.

\section{Leyes de la Dinámica de Sistemas}

En el proceso evolutivo del estudio de la dinámica de sistemas, se han descubierto comportamientos característicos de los sistemas en movimiento. A estos comportamientos característicos los llamamos leyes de la dinámica de sistemas. Las leyes predicen el comportamiento de los sistemas en movimiento, no de forma exacta sino de manera probable.

1. Ley de la fragmentación: Si dividimos un sistema en sus partes componentes, pierde dinámica. Una orquesta en la que cada uno de los músicos ensayara por separado, aun bajo el comando del mejor director, nunca sonará tan bien al reunirse como una que lleve mucho tiempo tocando junta, donde los músicos llegan a conocerse y a entenderse sin hablar.

Al departamentalizar una empresa en forma funcional se reduce la dinámica de la misma, por la pérdida de interconectividad y complementariedad. Las empresas cada vez tienden a aplicar algún tipo de departamentalización por procesos, donde cada proceso es un sistema completo, sin fragmentación, de esta forma aumenta la dinámica de la organización. La división de la empresa con los proveedores y clientes también es una forma de fragmentación, si logramos integrar proveedor, em- 
presa y cliente, el grado de dinámica del sistema total será mayor.

2. Ley de las presiones: Cuanto más se presiona un sistema, más presiona éste en sentido inverso. Estamos acostumbrados a presionar para conseguir algo que a esperar el tiempo necesario para obtener la respuesta natural. Y cuanto más esfuerzo hacemos, más esfuerzo es necesario para llegar al mismo resultado. Una medida de fuerza de empleados de una empresa, que lleva un tiempo prolongado de realización, es un tipo de situación difícil de resolver. Los que están tomando la medida de fuerza, sienten que no pueden abandonar su postura ni volver atrás sin conseguir resultados. Los directivos, a su vez, sienten que no pueden ceder porque significaría mostrar debilidad. Ambos llegan a una situación donde están presionando al sistema, y el sistema les devuelve más presión. El grado de libertad de ambas partes para negociar, será menor que antes de haber iniciado la medida de fuerza.

También presionamos a una organización cuando al no lograr el volumen de ventas deseado bajamos los precios para lograrlo sin analizar las razones de fondo de la baja de ventas. Después de un tiempo, la organización nos presiona mostrando resultados negativos o una perdida en el posicionamiento.

3. Ley de las mejoras aparentes: cuando presionamos a un sistema, este mejora para después empeorar. Una solución sintomática, típica forma de presión, dará resultados aparentes, pero empeorará el problema de fondo. Generar empleos públicos para reducir el desempleo en un municipio, provincia o país, en principio mejora la situación. En el mediano plazo, si esta decisión política no es acompañada por medidas de fondo, el municipio genera un déficit tal que no puede seguir pagando los sueldos ni asegurando los servicios básicos para la población.

Encontramos que en el último trimestre ha disminuido la demanda de nuestro producto, fundamentalmente porque no tiene buena calidad con lo que el porcentaje de recompra es muy bajo (es decir, clientes que repiten la experiencia de consumo luego de la compra inicial). Si respondemos coyunturalmente a esta situación, bajando los precios o haciendo publicidad para aumentar ventas sin corregir el problema de fondo -la baja calidad-, estamos forzando un sistema que tiene sus límites, y el efecto boca a boca, que amplifica la imagen de mala calidad Ilevara a una caída posterior más profunda que la inicial.
4. Ley de las demoras: Existe un tiempo ( $t$ ) entre la decisión y el resultado. Este tiempo ( $\mathrm{t}$ ) es la demora que se produce hasta lograr el resultado esperado. Si sabemos entender y esperar que esta demora se presente, tomamos medidas equivocadas, por un exceso de presión sobre el sistema.

Por ejemplo: una empresa que realiza una encuesta de satisfacción entre sus clientes y encuentra que, entre otros CEO, las mayores quejas son de atención al cliente. Contrata entonces a una empresa consultora de atención al cliente para que reentrene a las operadoras y diseñe un sistema que permita reducir los tiempos de respuesta. Un mes después de implementado, hace una nueva encuesta. Para su sorpresa, los resultados siguen siendo malos. ¿Qué hace entonces? Presiona a la consultora por mejores resultados, o cambia de consultora, o cambia las operadoras. Sin embargo, un análisis más cuidadoso de la situación mostraría que: a) Las mejoras requieren un tiempo para implementarse, especialmente cundo involucran cambios de actitud b) El cliente necesita un tiempo para notar estos cambios y no pensar que es algo casual, que una vez lo atendieron bien, sino que de ahora en más la atención a mejorado.

5. Ley de los ciclos: Un ciclo positivo será seguido de un ciclo negativo, luego de otro positivo, y así sucesivamente. Cuanto mayor sea la pendiente de la curva ascendente, mayor será la pendiente de la curva descendente y viceversa. Sucesivas generaciones de un mismo ciclo serán de menor duración que la anterior.

Muchos eventos naturales y procesos son cíclicos. Los ejemplos nos rodean, productos estacionales, acciones de la bolsa, ciclos de la economía, modas, etc.

El precio de algunas acciones parece moverse cíclicamente, y el observador atento puede descubrir los patrones en empresas de productos o servicios que se venden estacionalmente, especialmente si estas empresas presentan regularmente sus estados de resultados. Observe el ciclo de vida de los productos. En los inicios, en la etapa de introducción y crecimiento es creciente, por efecto de publicidad y la difusión boca a boca. Cuando el mercado se satura y se llega a la etapa de madurez, las ventas entran en una meseta, hasta que luego de un período, comienza la declinación. Este ciclo se repite una y otra vez con distintos productos, en distintos mercados. Quizás no en todas las ocasiones, pero si lo suficiente como para tomarlo en cuenta: cuanto más agresivo es el crecimiento inicial, más fuerte es la caída. 
6. Ley límite al crecimiento: Todo sistema tiene por lo menos un límite al crecimiento. Nada crece para siempre.

El crecimiento infinito producido por un proceso reforzador único puede existir solo en el campo de la teoría. En el mundo real, el crecimiento se detiene, antes o después. Cuanto más rápido es el crecimiento, antes surge el límite.

Todo proceso reforzador tiene al menos un límite, pero casi siempre hay más de uno. Aun cuando solo veamos un límite, al eliminarlo, aparecerá por lo menos otro más, que no era visible antes.

7. Ley de la palanca: si eliminamos el límite más importante, el sistema ganará dinamismo en forma más que proporcional. Como expresa la ley anterior, todo sistema tiene límites que detienen el crecimiento y habitualmente hay más de un límite que afecta al sistema. Poder entender cuál de los límites tendrá mayor efecto positivo al ser removido, es fundamental para aplicar el esfuerzo en el punto adecuado. Puede haber varias razones por las que un producto no se vende, pero al igual que no se ataca el fuego rociando agua indiscriminadamente en toda la extensión del incendio, las soluciones adecuadas pasan por algunos puntos principales, los que dependerán y de cada ocasión en particular.

Lo importante aquí es encontrar el punto de apalancamiento, es decir, descubrir cuál de todos es el límite más importante sobre el que hay que actuar. Si logramos detectar el punto de apalancamiento y eliminar el límite, obtendremos importantes resultados con menor esfuerzo.

De la mano con las leyes de dinámica de sistemas que nos ayudan a entender la complejidad, debemos tener un pensamiento sistémico, tomando al sistema como un todo para accionar, analizar y comprender, distinto del método científico que solo percibe partes de este "todo" y sin conexión entre sí.

El Modelo del Iceberg (adaptado de Anderson \& Johnson, 1997) puede ayudar a comprender la diferencia entre las respuestas sintomáticas -cuando se actúa sobre "la punta del iceberg", éste es el síntoma más evidente- y las respuestas estructurales de fondo -cuando se analizan el todo y las partes, y las posibles consecuencias de una decisión, así como las causas menos evidentes de un problema.

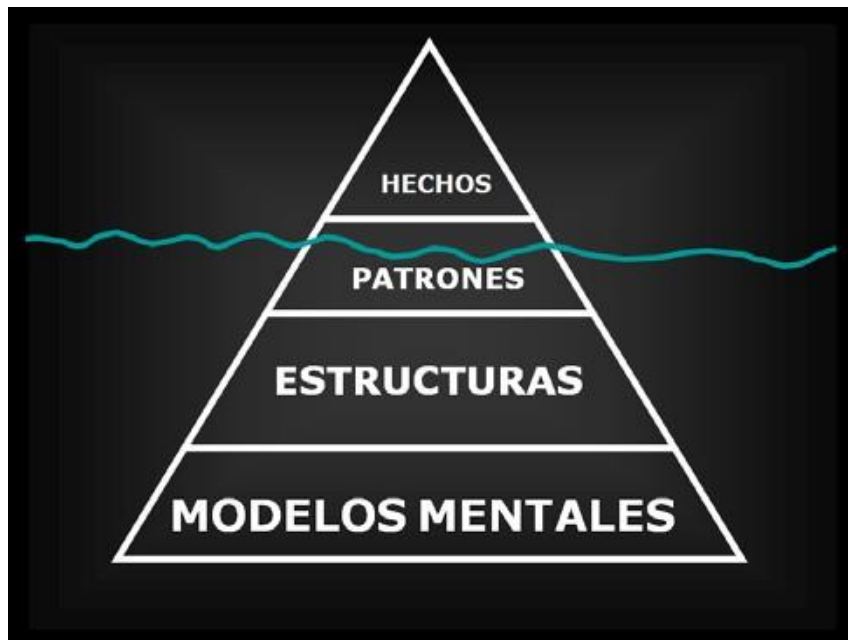

Hechos: el iceberg nos muestra que lo primero que percibimos son los hechos, por lo que reaccionamos y actuamos en función de éstos generando presiones que destruyen a la organización en su conjunto y a las personas que trabajan en ella. Por ejemplo, se vende muy poco un producto y lo elimino del surtido, ahí estoy trabajando en la punta del iceberg, con lo que veo a simple vista. Si analizo en profundidad puedo ver que no se vende debido a que está mal exhibido, por ubicación o espacio, y que además es muy valorado por la gente.

Patrones: un segundo nivel de comportamiento está dado por la toma de decisiones, ya no por los hechos sino por los patrones, es decir, comportamientos exitosos anteriores que copiamos o repetimos para buscar nuevamente el éxito. Muchas veces nos copiamos a nosotros mismos. Pensamos en una promoción exitosa que hicimos hace dos meses y la repetimos, pero también copiamos a un competidor en una categoría. El resultado es malo, ya que cuando hablamos de un contexto como el actual, las condiciones cambian permanentemente y las soluciones de ayer no remedian los problemas de hoy.

Estructura: Ilegar a las estructuras es llegar a la esencia, al fondo del sistema, donde vemos la relación entre las variables que están actuando y donde podemos analizar la interdependencia de esas variables. Al analizarla podemos encontrar los efectos que se producen al interrelacionarse las variables. Entender las interrelaciones es entender la no-linealidad, la complejidad y el dinamismo.

Modelos Mentales: la base más profunda del iceberg son los modelos mentales, y también, lo más difícil de cambiar. En general, nuestros modelos mentales no nos permiten ver la estructura sistémica, sólo percibimos lo más evidente, los hechos y a lo sumo, los patrones. Debemos utilizar también la idea de David Bohm en cuanto al "potencial cuántico", las infinitas posibilidades 
de creación e innovación que tenemos si nos conectamos y relacionamos en forma permanente con otros; el potencial cuántico es un potencial que todos tenemos y que tiende a infinito (Peat, 1997). Como ejemplo de esto podemos ver las infinitas posibilidades que tenemos al utilizar Internet; Las Nuevas Ciencias, nos enseñan a entender la ambigüedad y también a entender la no linealidad de las relaciones, las bifurcaciones y amplificaciones que permanentemente existen en los entornos dinámicos de la actualidad.

Normalmente se manejan las organizaciones pensando en los hechos, en las cosas que pasan, tomamos decisiones basándonos en ellos, pero nos cuesta mucho llegar a la estructura de las relaciones entre las personas y los objetos para poder tomar decisiones de una forma completamente distinta.

\section{Motor de crecimiento}

Hace ya varios años que desarrollamos y venimos trabajando con el modelo del motor de crecimiento, partiendo de las ideas de dinámica de sistemas, para entender el funcionamiento de una organización. La idea central de este modelo es entender la empresa como impulsada por un motor que la lleva hacia el objetivo propuesto, esto es, su propósito estratégico. Este motor es la rueda operativa que está liderada por el producto o servicio central.

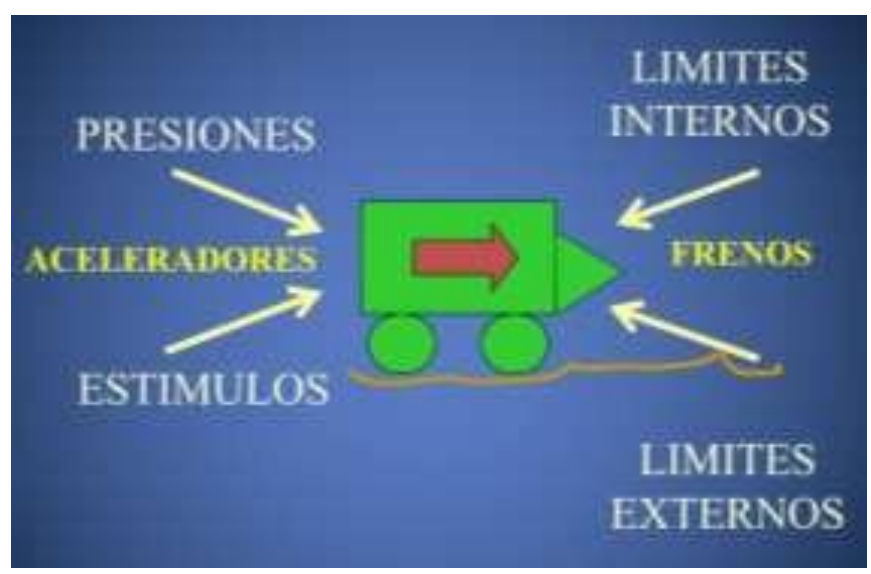

Sobre el motor actúan dos fuerzas básicas, de distinto orden: aceleradores y frenos. Los aceleradores pueden clasificarse en presiones y estímulos, en tanto que los frenos están clasificados como límites internos y externos al crecimiento.

\section{Aceleradores-Presiones}

Las presiones son aquellas que actúan sobre el motor de crecimiento acelerándolo, sin tener en cuenta los efectos secundarios que puedan producirse, más allá de los buscados. Son las acciones que se emprenden para atacar el síntoma, sin observar el sistema completo.

La presión es un modo de reacción, se busca solucionar los problemas de manera rápida. La velocidad del contexto hace que muchas se tomen decisiones casi por reflejo, sin hacer un estudio más profundo de las ramificaciones de la misma. Toda decisión impulsiva, tomada sin pensar en sus efectos futuros, puede ser considerada una presión.

Se vende poco, bajemos los precios o hagamos más publicidad. Los números no cierran, bajemos los costos. Claro que, a veces, una presión puede funcionar. Pero en estos casos, más que estar orgullosos por nuestra habilidad deberíamos agradecer al cielo por nuestra buena fortuna.

\section{Aceleradores-Estímulos}

A diferencia de las presiones, los estímulos aceleran el motor de crecimiento, pero teniendo en cuenta la complejidad del sistema. Un estímulo puede ser definido como un acelerador de largo plazo. Podemos decir también que son todos los procesos que se realizan para modificar y redefinir el motor de crecimiento, analizando su funcionamiento global, como en la incorporación de un nuevo producto, en un cambio de una trayectoria estratégica, o en la transformación de la estructura.

Las organizaciones deberían actuar guiadas por estímulos y nunca por presiones. De esta forma, es posible conducirlas a un crecimiento sostenible en el tiempo, teniendo en consideración cómo afectan sobre ellas las leyes de la dinámica de sistemas y cuáles son los puntos de apalancamiento que la mantienen en funcionamiento.

\section{Frenos-Límites Externos al Crecimiento}

Todo sistema tiene sus límites, por lo tanto toda empresa los tiene. Los límites externos al crecimiento son los procesos compensadores, externos a la empresa, que frenan o desaceleran el avance del motor de crecimiento.

Muchas veces son los más difíciles de eliminar, porque dependen de muchas variables que no podemos controlar. Hay algunos factores como la saturación de un mercado, la influencia de la competencia, cambios de conductas del consumidor, que pueden estar un poco más a nuestro alcance y sobre los que podemos accionar. 


\section{Frenos-Límites Internos al Crecimiento}

Son los límites que la propia empresa pone a su crecimiento, por desconocimiento, por incapacidad o por falta de una visión clara de los problemas. Los límites internos pueden ser estratégicos, estructurales, culturales operativos, etc. Algunos ejemplos: falta de posicionamiento, atención deficiente al cliente, mal surtido, exhibición poco legible, modelos mentales inadecuados, subculturas heterogéneas, altos costos, comunicación externa inadecuada.

Tomando la empresa como un motor de crecimiento que tiene como objetivo a largo plazo su propósito estratégico, interactúan sobre él aceleradores y frenos. Ante una disminución en la velocidad de avance del motor, aparece, casi siempre, la tentación de utilizar las presiones como aceleradores que impulsen al motor a mayor velocidad.

Sin embargo, en la gran mayoría de los casos, la disminución de la velocidad esta ocasionada por la existencia de límites al crecimiento. Por lo tanto, si forzamos al motor aplicándole presiones con los frenos puestos, no conseguiremos avanzar más que en el muy corto plazo. Si insistimos con la aplicación de presión en esas condiciones, terminaremos destruyendo el motor.

La solución está en destrabar primero los límites al crecimiento para así poder crecer naturalmente, sin precipitar el crecimiento. El motor no puede avanzar con los frenos puestos, ya que resultaría dañado. Es muy importante descubrir cuál de todos los límites al crecimiento es el más importante ya que destrabando éste, la situación puede mejorar exponencialmente.

El uso de estímulos sirve para redefinir y actualizar el motor de crecimiento. Especialmente, es muy útil cuando nos enfrentamos con límites al crecimiento externos, para pensar en nuevos caminos para llegar a nuestro objetivo. La reacción de los estímulos es lenta. Generalmente, se presentan grandes demoras desde que introducimos un estímulo hasta que obtenemos el resultado. En cambio, las presiones son de reacción mucho más rápida. Por su tipo de acción, deben ser utilizadas con mucha moderación o no ser utilizadas, ya que pueden destruir al sistema.

\section{Modelos de negocio (Modelos de organiza- ción)}

Es el modelo que toma cada empresa u organización en función de la estrategia, para darle forma a los productos o servicios que genera. Si es una organización sin fines de lucro se llamará "Modelo de Organización" si es un País será "Modelo de País"

Como clientes emitimos juicios de valor sobre la mayoría de los negocios con los que interactuamos, sean estos una cadena de restaurantes, de hoteles, una línea aérea, un supermercado, un shopping, una tienda por departamentos, una juguetería, etc. Los juicios de valor son en función de si esta ordenada y limpia la sucursal, si tienen faltantes en el surtido, si tuvieron que esperar mucho para que ser atendidos o para poder pagar sus compras, si los precios son altos, si tienen buena atención o no, si tienen o no servicios complementarios. así podríamos seguir más y más con una vasta cantidad de ejemplos que tenemos porque todos somos clientes y sin pensar en un modelo de negocio, estamos hablando de él permanentemente.

Esto que ve el cliente es el modelo de negocio real, el que el cliente vive en su tiempo dentro del local o es el modelo de negocio deseado fruto de la elaboración del marco estratégico. De esta manera se presenta la dualidad existente entre el modelo de negocio real y el deseado por la empresa. El ideal es lograr que el modelo deseado sea lo más similar posible al modelo real, esto no es fácil es realmente complejo porque toda la organización tiene que intervenir para logar ejecutar la estrategia en forma de modelo de negocio deseado. De esta forma el liderazgo es fundamental para lograr que lo que soñamos y apostamos, sea muy parecido a lo que logramos.

Los componentes del modelo de negocio son aquellos que forman parte del llamado Marco Estratégico, la Visión, el Posicionamiento y la Estrategia. El resultado de la formulación del marco estratégico será la determinación de surtidos y precios de productos, formas de exhibición, promociones y formas de comunicación propias del negocio que llevarán a pensar y formular un modo de operación del mismo.

Luego de plasmar esto tenemos que definir cómo ganaremos dinero, cómo financiaremos todo lo que proponemos y aquí es donde aparecen los Modelos de Rentabilidad.

Llamamos modelos de rentabilidad a las distintas formas que una empresa u organización, tiene de generar ingresos. Estos modelos pueden usarse de forma simultánea dentro de un mismo negocio, no necesariamente debe elegirse uno, sino que de acuerdo a cada circunstancia se utilizaran los que se consideren más adecuados. 


\section{Modelos de Rentabilidad}

1. Modelo Tradicional: la forma tradicional de generar rentabilidad viene dada de la siguiente manera: Rentabilidad=margen $\mathrm{x}$ rotación. Las variantes en este modelo se encuentran en la modificación de sus variables, una forma puede ser tener un margen pequeño y aspirar a rotar mucho y su opuesto sería una con margen de medio a elevado con menos pretensiones de rotación de producto. Esto lo podemos ver en restaurantes en donde algunos deben tener una ocupación del $80 \%$ de sus mesas para ser rentables dado que ofrecen precios bajos y por consecuencia marginan bajo mientras que otros restaurantes marginan alto, por diferentes causas, y teniendo menos rotación que el caso anterior son muy rentables.

2. Modelo de Rentabilidad por Marca: en este caso el elemento sobre el cual se apalanca para generar más ingresos es la marca. Cuanto más prestigiosa y exclusiva sea la marca, más alto voy a poder marginar. Generalmente se da en combinación con otras y para lograr esto debemos trabajar fuerte en elevar la diferenciación percibida por los consumidores a través de acciones llevadas con coherencia y consistencia a través del tiempo, generando una estructura fractal. De esta manera el precio que se podrá cobrar será mayor.

3. Modelo de Rentabilidad por publicidad: es un modelo que permite generar ingresos a través de anuncios, carteles y cualquier tipo de material que promocione otra marca. Esto es utilizado como principal forma de generar ingresos en internet, es el modelo utilizado por diarios, revistas y distintas redes sociales.

4. Modelo de Rentabilidad por Especialización: aquí el hecho de ser referente en una categoría o grupo de categorías de productos me permite ser más rentable. Un ejemplo puede ser un especialista en Quesos y Fiambres cuyos elevados precios se atribuyen al grado de conocimiento y asesoramiento que el personal tiene sobre los distintos productos, como también la posibilidad de posicionar su marca como especialista y comercializar solo productos con su marca dejando sin posibilidad de comparación con los fabricantes tradicionales que existen en el mercado.

5. Modelo de Rentabilidad por soluciones: es un modelo utilizado por aquellas empresas que son proveedoras de insumos. Es la mejor forma de sa- lir del commodity ya que muchas veces este tipo de empresas se encuentran en permanente guerra de precio con competidores debido a las licitaciones emitidas por sus clientes que obligan a que esto pase. El punto aquí es romper con ello e intentar generar mayor valor para ambos brindando una solución o conjunto de soluciones que le permitan al fabricante utilizar el insumo de la manera más eficiente posible, sin perdidas y con el asesoramiento necesario.

6. Modelo de Pirámide de Producto: este modelo de rentabilidad se destaca por tener un producto debajo del costo y otros al mismo costo pero con precios escalonados en forma de pirámide. La forma de llevarlo a cabo es teniendo un personal de ventas que sepa asesorar y vender los productos de mayor valor, de otra manera no funciona. El producto debajo del costo es aquel que se va a promocionar fuera del local, sea en vía publica, en los medios, etc, supongamos que hablamos de un valor inicial de $\$ 30$, con el mismo costo que el modelo de $\$ 30$ tendremos uno por $\$ 40$, otro por $\$ 50$, otro por $\$ 60$ y uno más alto por $\$ 70$. Las modificaciones de precio irán acompañadas por pequeños cambios en el producto. Este modelo de rentabilidad aspira a generar tráfico con un buen producto a un precio más que interesante y luego una vez que el cliente está en el punto de venta intentar vender los productos de mayor valor para promediar un ticket de $\$ 50$.

7. Modelo de Complementariedad: es una forma de generar ingresos a través de productos o servicios que son complementarios al core del negocio. $\mathrm{Si}$ tengo una cadena de cines a través de este modelo puedo evaluar vender comida y bebida antes, durante y después de cada función, también se puede analizar la posibilidad de vender juguetes de personajes de las películas. Si soy una empresa que fabrica relojes tengo que intentar complementar mi negocio con la de venta de correas, protectores y accesorios relacionados con el producto principal. Es vital entender que muchas veces estos productos o servicios complementarios son los que hacen un porcentaje fuerte de la rentabilidad del negocio en general.

8. Modelo de Rentabilidad por multiplicación: se trata de reproducir y multiplicar un concepto de diferentes formas. Es un modelo que es usado por empresas como Disney que llevan personajes como Mickey a la venta de DVD's, peluches, relojes, remeras, parques de diversiones y otras 
formas en donde lo importante es multiplicar el personaje por la cantidad de lugares que se pueda para generar mayores ingresos. La clave aquí es generar una relación simbiótica fuerte entre el consumidor y lo que voy a multiplicar, un concepto, un personaje o cualquier otra cosa.

9. Modelo de Rentabilidad por Liderazgo local: si tengo importante presencia en una zona determinada es probable que la comunidad piense que soy el líder en la provincia, estado o hasta en el país. Cada vez ocurre menos debido al efecto de internet y las redes sociales, pero cuando un minorista se enfoca en una zona, supongamos una pinturería, va a llenar la zona con sus sucursales. La gente al ver tantas sucursales en esa zona creerá que se trata de una gran cadena y esto llevará a generar mayor confianza al momento de la elección del lugar de compra. Insistimos en que cada vez se da menos porque la gente no se deja llevar por estas cosas en las grandes metrópolis, no así en zonas del interior en donde se puede aplicar un modelo de este tipo.

10. Modelo de Rentabilidad de Precio Cero: es uno de los modelos más interesantes y cuya explosión se está dando en este momento con las redes sociales e internet. Rompe con la ortodoxia de todas las formas de generar ingresos tradicionales. En este modelo voy a generar ingresos a través de distintos modelos de rentabilidad, logrando que el consumidor final no pague, sino que el negocio este financiado por otras empresas y el valor generado por la masividad de las relaciones que se dan entre los clientes/consumidores/participantes. Están comenzando a aparecer ejemplos y uno de ellos es la línea aérea irlandesa Ryanair que pretende llevar el precio del pasaje a $\$ 0$. Su negocio va a estar financiado y sostenido por empresas que quieran colocar publicidad dentro de los aviones, las investigaciones de mercado que puedan completar los clientes, la inmensa base de datos generada, los extras que se le cobraran a los clientes formaran parte de los ingresos de Ryanair pero no cobrarán sus pasajes. Se trata de comenzar a hacer uso de la masividad que genera en la gente lo GRATIS. Hoy es un modelo que está abierto para que lo puedan probar muchas empresas y negocios nuevos, es realmente interesante y muy atractivo.

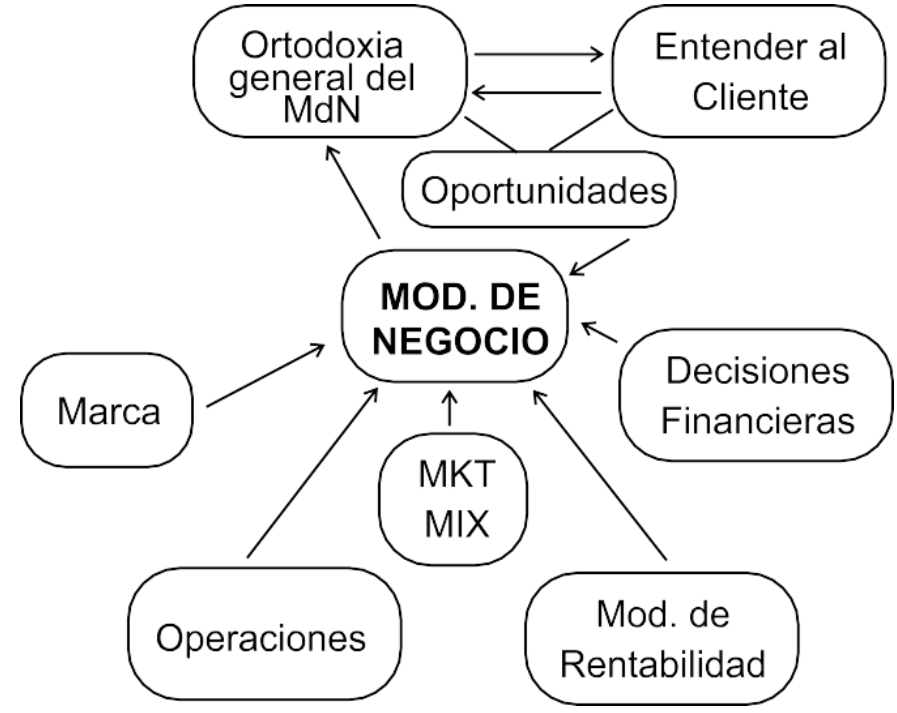

Los modelos de rentabilidad, tanto como las formas de operación, la marca, el mix de marketing y las decisiones financieras, en conjunto con la filosofía del negocio van a dar forma al modelo de negocio. Este modelo de negocio debe ser cada vez más dinámico, no nos podemos quedar conformes con lo que hacemos sino que debemos estar en la búsqueda permanente de oportunidades para innovar de manera evolutiva y disruptiva dentro del modelo de negocio.

\section{Innovación disruptiva y evolutiva}

Innovamos de forma evolutiva cuando pretendemos introducir cambios pequeños en lo respectivo al producto/ servicio y sus facilidades, manteniendo las reglas del juego. En la Matriz de Apuestas podemos observar que mantener el estado del juego implica que no se busca un cambio radical en los patrones de consumo de los clientes y por otro lado que la fuerza de la jugada es baja. Los cambios en la fórmula del producto, nuevas especificaciones, rediseño de packaging, etc, son innovaciones evolutivas.

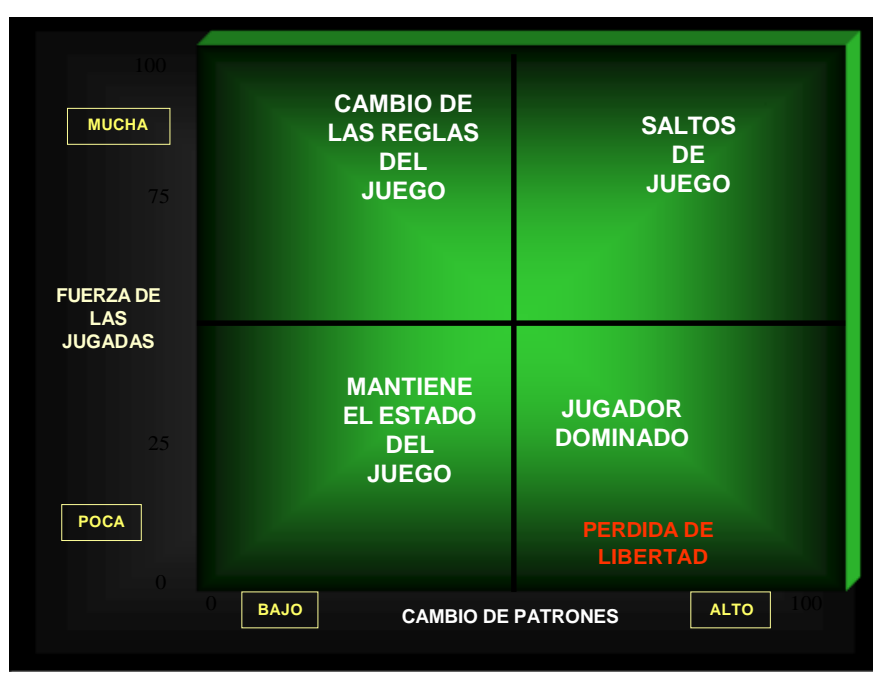


Ahora bien, veamos que ocurre con la innovación disruptiva. Esta innovación implica hacer algo completamente diferente a lo que hace la competencia, a lo que hace el mercado, romper con la ortodoxia general de modelo de negocios existentes en el mercado, implica un salto de juego, jugar desde un lugar distinto, abrir una nueva matriz. Decidimos innovar de forma disruptiva cuando vemos que existen oportunidades que no son capitalizadas por la ortodoxia de los modelos de negocio actuales en el mercado.

Como cualquier innovación primero tenemos que partir del entendimiento de las necesidades de los clientes, actuales y futuros, allí es donde visualizamos las oportunidades. Si no partimos de este punto nuestra disrupción tendrá bajo efecto en el mercado porque si no entendemos al cliente difícilmente logremos cambiar sus patrones de consumo.

Partimos de allí para luego romper la forma tradicional y generar un salto de juego. Para lograr un salto de juego necesitamos, como comentamos anteriormente, que haya un alto porcentaje de cambio en los patrones y las formas de compra y consumo, si no logramos este cambio, no tendremos éxito. Esto puede pasar y ocurre muchas veces cuando queremos ser disruptivos pero no tenemos en cuenta al cliente, creemos que por la simple razón de que se trata de algo nuevo la gente se sentirá atraída y comprará.

Una innovación disruptiva es exitosa cuando se logra un salto de juego y se deja al resto de los jugadores como dominados, como obsoletos y viejos y los consumidores y clientes modifican sus hábitos de consumo tomando lo nuevo.

\section{Visión, posicionamiento y estrategia}

Si no tenemos clara la Visión, no sabemos a dónde queremos llegar, no tenemos un sueño claro, entonces no tiene sentido tener una Estrategia.

Si por otro lado tenemos una Visión clara pero no tenemos claro que Posicionamiento queremos lograr, tampoco vamos a poder tener una buena estrategia, por eso primero tenemos que tener muy clara la visión, tenemos que ver ahora lo que queremos lograr en el futuro y por otro lado tenemos que tener muy claro cómo queremos que nos vean los jugadores clave, es decir tener un Posicionamiento muy claro también.

Siguiendo la Teoría del Caos, el Posicionamiento debe formar una "Estructura Fractal Solida" y coherente y consistente en el tiempo.
"El posicionamiento es percepción, es auto semejanza, es formar una sola "estructura fractal", donde desde cualquier ángulo debemos ver lo mismo. Mirándolo desde la tienda, desde el proveedor, desde el cliente o desde el surtido, o el precio, la exhibición o la promoción." Serra, Murphy (2015)

En la siguiente foto vemos la estructura fractal de las hojas en la naturaleza.

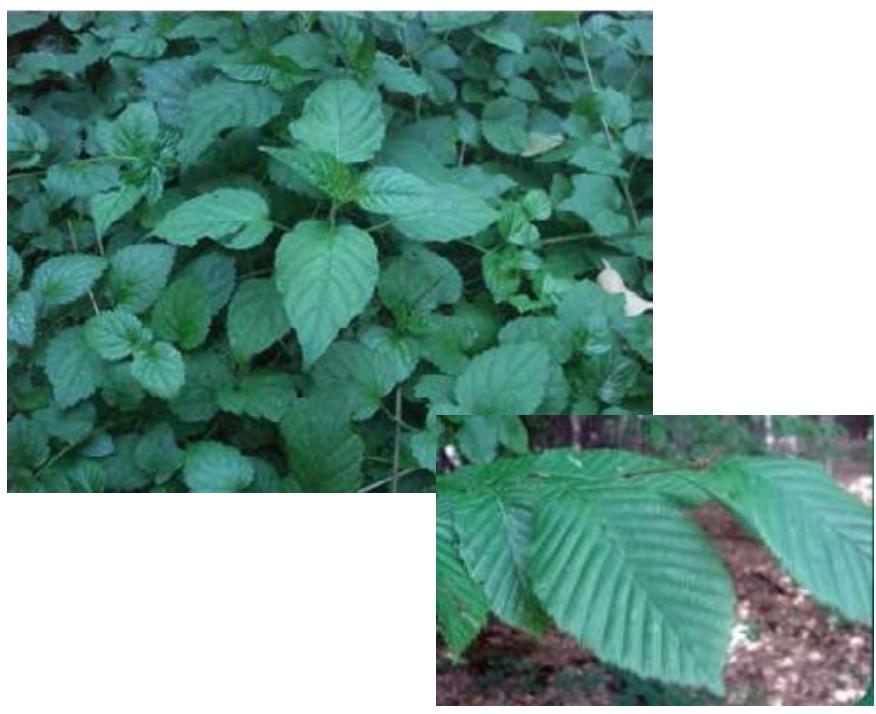

\section{Fractales}

Del latín "FRACTUS". Son objetos cuya estructura básica, fragmentada o irregular se repite a diferentes escalas. (Mandelbrot, 1975)

\section{Propiedades}

- Autosemejanza.

- Dimensión fractaria.

- Forman estructuras sólidas.

- Están en la naturaleza y en la vida real.

\section{Los Fractales y el Posicionamiento}

Los fractales en la naturaleza nos muestran formas y colores que logran que nuestra mente los capte por repetición y autosemejanza y por lo tanto podamos distinguirlos con un nombre.

Esto genera el concepto de posicionamiento, una estructura fractal sólida y permanente en el tiempo logra el posicionamiento deseado.

Una manzana es diferente a una pera por su forma, sabor y color 

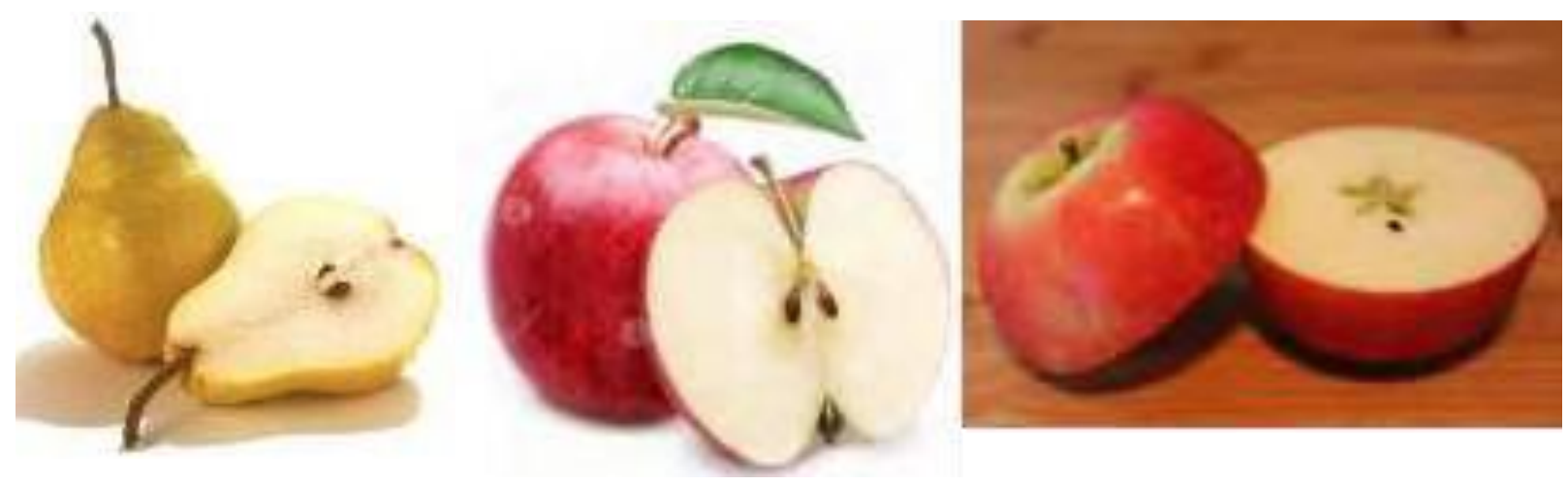

\section{La Estructura Fractal de Google}

- GRATIS

- FÁCIL

- PRÁCTICO

- ÚTIL

- INNOVACIÓN

Si la estructura fractal de Google se rompe, Google deja de ser Google, si no innova, se rompe el fractal.

Poder mantener una estructura fractal a lo largo del tiempo no es fácil, requiere de Dinamismo, Innovación, Foco, Claridad y Plasticidad.

Para desarrollar una estrategia sostenible en el tiempo se requiere mantener en forma dinámica una estructura fractal sólida.

\section{Conclusiones}

La estrategia es simple y compleja a la vez, tenemos que trabajar con Pasión para generar Vitalidad en la organización, una organización con Pasión genera energía, la energía movimiento y el movimiento Vitalidad y Dinámica.
Por otro lado, tenemos que tener Foco, foco en lo importante y trabajar con Intensidad Relajada, si la organización es intensa pero estresada no puede desarrollar nunca una estrategia, se moverá a través de las Presiones y sus consecuencias.

Por último, para lograr que una estrategia logre sostenerse en el tiempo y conseguir los resultados esperados debe lograr fluidez, la estrategia debe fluir dentro de la organización sin trabas y sin las estructuras que destruyen todos los nuevos proyectos e innovaciones.

La estrategia tiene que liderar la innovación en todas sus posibilidades y lograr que la gente trabaje contenta y con Pasión manteniendo la Estructura Fractal necesaria para mantener y desarrollar el Posicionamiento buscado. El modelo mental holistico es fundamental para lograr el éxito en cualquier organización. 